\title{
The Exploration of Utilization and Development of Energy in Rural Planning
}

\author{
Yifei Li, Ning Wang \& Shuang Su \\ Urban and Rural Planning, Agricultural University of Hebei, Hebei, 071001, China
}

\begin{abstract}
It is proposed in the parsing of energy conservation measures for energy strategy and its relationship with the rural planning: the utilization and development of rural energy is the key to the implementation of the national strategy for sustainable development. With the means of rural planning, we must unified the relationship between energy, economy and environment. While developing and using various energy sources, we should also fully consider the agro-ecological and environmental benefits. Besides, the implementation of clean developing and utilizing projects of rural energy is as well an important measure to control air pollution.
\end{abstract}

KEYWORD: energy conservation measures; clean energy; development and utilization of energy

\section{BACKGROUND OF ENERGY UTILIZATION AND DEVELOPMENT}

\subsection{China's Energy Crisis}

China's energy consumption rate is so faster than other countries that energy depletion threat may come earlier and more seriously. Thus, the external energy pressure caused by the growing demand for foreign energy forces us to find a break-out way to solve the energy crisis. Accompanied by rapid economic development and sustained growth of energy demand, greenhouse gases emission produced by fossil fuel combustion caused heavier and heavier pressure to the environment. Faced with current serious environmental crisis brought by fossil energy consumption, the adjustment of energy structure is imminent.

\subsection{China's Energy Strategy}

At present, compared to the past energy-supplyoriented "open source type" energy strategy, our country's new sustainable-development-oriented energy strategy has two fundamental shifts:

Firstly, it requests "energy" to be placed first in the energy development strategy. This is because China's economic and social development is in transition period, during which the rapid development of industrialization, informatizaion and urbanization is urgently promoting agricultural modernization. Conservation and efficiency can not only ease the contradiction between energy supply and demand and ensure energy security, but also has a dual effect of protecting the environment; Secondly, environmental restrictions of energy use will be an important internal factor in the decisionmaking of energy strategy in the future.

\section{SIGNIFICANCE OF ENERGY PLANNING}

Currently, rural energy development is lagging behind by extensive energy use, lower utilization levels and weak energy infrastructure, which severely restrict the achievement of the goal of new rural construction. In order to advance new rural construction, improve rural living environment and improve the living quality of farmers, we must strengthen the construction of rural energy, promote clean and efficient conventional energy utilization, develop and utilize renewable energy and improve the overall energy level of the countryside.

Developing rural energy planning can ease the energy shortage situation, ensure national energy security and help promote recycling economy achieve a win-win economic and ecological benefits. Energy Smart planning of Wang Nao Village achieves optimal results by minimizing the cost on the basis of retention local style, which not only changed the local way of life and production, but also promoted the new emerging industries such as new agriculture and tourism ${ }^{[1]}$.

Wang Nao Village has a long historical context and unique mountain specialties, achieving village 
intelligent planning by adjusting the coordinated development of resource, environment, economy and humanity. Reasonable planning and optimization configuration of rural energy is the key to resolving the contradiction between rapid economic development and energy shortage, the key to coordinating urban-rural gap and rational use of energy resources. Ultimately we can achieve the goal of beautiful countryside construction with Chinese characteristics.

\section{ENERGY AND ENERGY CONSERVATION PLANNING OF WANG NAO VILLAGE}

\subsection{Current Situation of Wang Nao Village}

Wang Nao Village, located in the west of Taihang Mountain area of Shahe City, Hebei Province, is China's famous ancient historical and cultural village with Taihang characteristics, which protects and inheritances outstanding historical and cultural heritages. By 2013 Wang Nao Village has a population of 853 (257 families). Its industries mainly are mining, materials building, farming and growing. Mountain villages to develop character, history and culture of ancient villages tourism mainly to the development of organic agriculture, processing industry, supplemented by features, show green, ecology, low-carbon, history, culture characteristics.

Wang Nao Village status quo fuel use is unreasonable, residents dispersed heating, fuel mainly firewood, coal-based fuel use is unreasonable, not only failed to save energy, while gas after combustion emissions impact on the environment is also large, can not be achieved the basic requirements for the protection of historical and cultural village, so the problem of energy planning becomes necessary to address the constraints of local development.

\subsection{Energy Use and Energy-Saving Measures}

\subsubsection{The Residential Energy-Saving Design}

(1) Building materials: village located in the Taihang Mountains area is extremely rich in stone, where the houses of local materials, built a very mountainous original ecological characteristics of stone buildings. Both conserve resources in turn supplies their own artistic nature on its head, passing the local context, full of natural beauty, the beauty of the material shows a unique stone art.

(2) Wall insulation: New houses with new insulation wall materials; exterior doors and windows with double glass.

(3) Roof insulation: Take pitched roof insulation technology, to increase the tightness of the roof, and additional insulation.
As can be seen from Fig 1 .

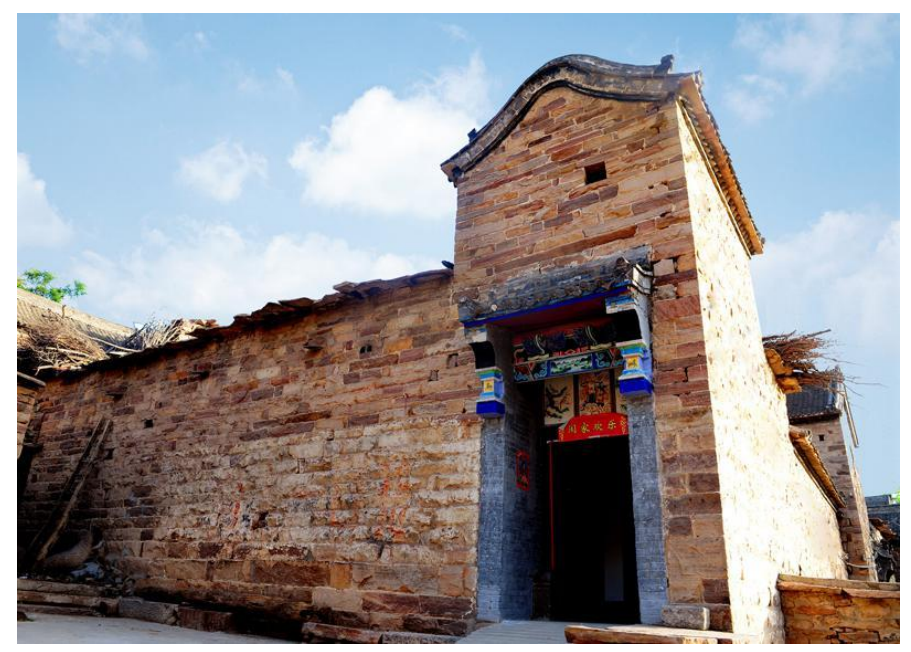

Fig. 1 The stone buildings

\subsubsection{Use of Clean Energy}

(1)The use of solar energy

Resource use classification of solar total five regions, Shahe City in the second class area, total annual solar radiation equivalent to burning coal equivalent (200 to $230 \mathrm{~kg}$ ), it can be said Wang Nao Village has abundant solar energy resources. Specific measures for utilization of solar energy are: Solar water heater installed on the roof; New residential use of solar lighting systems; landscape lighting using solar energy facilities ${ }^{[2]}$; through a variety of economic and technical comparison of energy, combined with the status of village lifestyle and different conditions and needs of residents per household, for the Wang Nao Village green energy is solar energy. As can be seen from Fig 2.

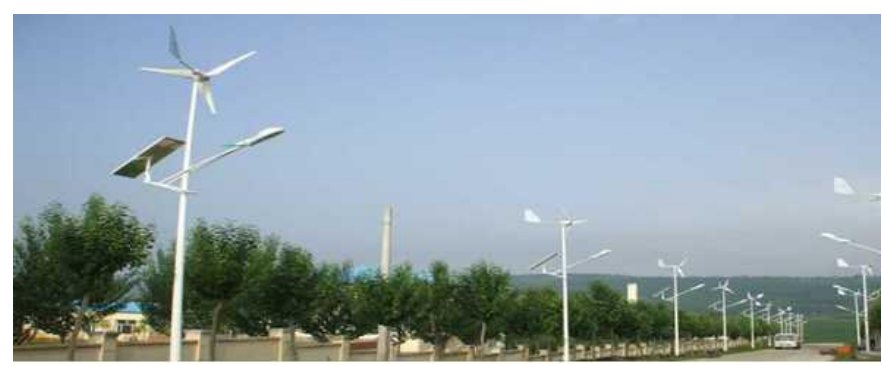

Fig. 2 The use of biogas

\section{(2)The use of biogas}

In a separate area northeast of west Wang Nao New Village arrangement biogas station, adjacent to the farm plan as a gas source Wang Nao Village, changing the direction of the village residents with choice of fuel. Planning use of biogas as a living mainly by gas, electricity as an alternative energy source. Biogas as the main energy of life, the summer will be a small part of the household use of solar hot water bath. As can be seen from Fig 3 . 


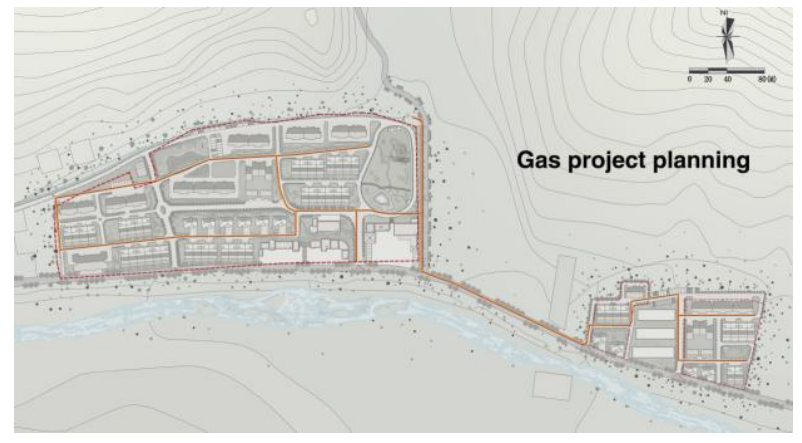

Fig. 3 Gas project planning

Economic effects: new efficient digesters an 8 to 10 cubic meters of 3 to 5 people solve farmers nearly a year of living fuels, coal $2000 \mathrm{~kg}$, saving about 200 degrees.the annual fuel savings of 300 yuan, saving electricity 100 yuan.

Ecological effects: development and utilization of biogas, which can effectively alleviate the shortage of rural energy, protection and restoration of forest vegetation, promote ecological environment improvement.

Sanitation effects: both human and animal feces with biogas treatment insecticide sterilization, but also get high quality energy and fertilizer.

\section{INSPIRATION OF ENERGY PLAN IN WANG NAO VILLAGE}

\subsection{Use of Effective Resources}

Through the development of energy planning, energy infrastructure so tilted to the countryside, improve the outskirts of the energy supply system to enhance the level of rural energy use; local conditions to guide the rural supply and upgrading of traditional energy consumption patterns, a variety of ways to solve simultaneously rural energy problems. Vigorously develop the use renewable energy sources, not only can ease the energy crisis, improving rural living energy structure, increase rural quality of energy supply, but also to put agriculture ecology, economy the road of healthy development. Gradually narrow the gap in energy supply and consumption levels among urban, rural and urban, suburban and rural areas to enhance the attractiveness and improving people's living standards.

Vigorously develop energy plan is to provide an effective vehicle for the use of agricultural resources, agricultural systems for material and energy efficiency efficient conversion cycle has the most direct effect, so that the level of integration of agricultural planting towards new heights, becoming an important way to the development of circular economy. Wang Nao Village built digesters Meanwhile, lavatories, changing kitchen, changing circle, changing homes, so that the land, solar and biomass energy resources more efficient use of the agricultural "waste" (straw, manure, garbage) into agriculture "three material" (fuel, feed, fertilizer), to achieve a social ecological farmers to get rich objectives and promote the harmonious development of production and living, ecology, agriculture and the rural economy has become a new growth point.

\subsection{Effective Solution of the "three dimensional rural issues"}

For a long time the policy priority to the development of the city, resulting in the suburbs and rural infrastructure conditions significantly behind urban areas. Such regional disparities and urbanrural dual structure restricts the coordinated economic development, affecting the social stability. According to the "people-oriented" and "urban and rural development, regional development", the spirit of the CPC Central Committee proposed, it should achieve regional equality in terms of energy use, strengthening suburban and rural energy infrastructure construction, improve the living and production conditions, and gradually narrow the urban-rural gap. A major component of energy planning is to optimize energy allocation of resources, implementation of energy infrastructure space layout, therefore, to co-ordinate regional and rural development will play an important role.

\subsection{Enhancement of the Environment}

Vigorously develop energy plan is to improve the environmental situation in rural public health, effective measures to protect the ecological environment. Can be changed in the short term at low cost traditional way of life of farmers, farming brought solve environmental pollution, improve the living environment ${ }^{[3]}$. Little digesters changed the rural courtyard, street sanitation manure cross-flow, so that village appearance, appearance households Yung households fundamental change imperceptibly. Energy development plan, is to carry out the ecological environment, optimize the structure of rural, peasant life long-term plan to solve the fuel problem. Especially in rural biogas, both clean fuel for farmers to provide quality of life, but also to promote economic development in the courtyard. Build a digester to build an eco-loop system for handling waste, reduce deforestation and fertilizers, application of pesticides has the most direct effect.

\subsection{Combination of Business, Industry and Tourism}

Wang Nao Village energy planning is a fully integrated body, reflected in many aspects such as industrial restructuring, business developing and tourism developing, which requires rational energy planning as a fundamental prerequisite ${ }^{[4]}$. The 
adoption of new residential construction, commercial construction, parks and ecological landscape construction, as well as the retention customs, inheritance of rock culture and insurance of ancient village culture security, are a necessary prerequisite for the development of village tourism.

\section{CONCLUSION}

Through the discussion of the Wang Nao Village energy planning, we can preliminarily draw the following conclusions: With the increasing influence by energy on China's economy, society and environmental protection, supply and use of energy is already rising from a departmental and industrial issue to an overall and comprehensive strategy issue. Rural planning should adopt effective energy-saving measures to develop and utilize energy. At he same time, we should fully consider the agro-ecological and environmental benefits min order to achieve coordinated development of rural economic development and environmental protection.

\section{REFERENCES}

[1] The problems of Energy construction to be solved in rural areas. Financial Research of GuangXi's rural.

[2] Jonathan $R$ G,Koomey G.Using energy scenarios to explore alternative energy pathways in California. Energy Policy. 2005.

[3] C Cormio, M Dicorato, A Minoia, etc. A Regional Energy Planning Methodology Including Renew able Energy Sources and Environmental Constraints. Renew able and Sustainable Energy Reviews. 2003

[4] Makoto Kanagawa, Toshihiko Nakata. Analysis of the energy access improvement and its socio-economic impacts in rural areas of developing countries. Ecological Economics. 2007 